\title{
Differential redundancy gain in onset detection versus offset detection
}

\author{
RICO FISCHER \\ Technische Universität Dresden, Dresden, Germany \\ AND \\ JefF Miller \\ University of Otago, Dunedin, New Zealand
}

\begin{abstract}
In a visual simple reaction time paradigm with attention divided between the left and right visual fields, $r e$ dundancy gain refers to the finding of faster responses to stimuli presented in both fields than to single stimuli. The present study investigated whether the effects of low-level perceptual processing affect the redundancy gain by comparing the detection of onsets versus offsets. In different blocks, participants responded to left and right visual field stimuli that either appeared (onset) or disappeared (offset), with a single stimulus change in some trials and two redundant stimulus changes in others. With onset stimuli, the results replicated previous redundancy gain effects. In contrast, there was much less redundancy gain when participants responded to stimulus offsets. This finding suggests that redundancy gain is sensitive to low-level perceptual characteristics, such as onset versus offset presentation of stimuli.
\end{abstract}

Detection responses in simple response time (RT) tasks are known to depend on the number of target stimuli that are presented (see, e.g., Blake, Martens, Garrett, \& Westendorf, 1980). A typical finding is that RTs are shorter when two redundant targets are presented simultaneously than when a single target is presented. In a visual simple RT task with attention divided between the left and right visual fields, for example, the redundancy gain effect is the RT advantage for bilateral presentations as compared with unilateral ones (e.g., Corballis, 2002; Egeth \& Mordkoff, 1991; Miniussi, Girelli, \& Marzi, 1998). Similar redundancy gain effects have also been observed with redundant target stimuli in different modalities (e.g., Diederich, 1992; Diederich \& Colonius, 1987) and in choice RT tasks (Grice, Canham, \& Boroughs, 1984).

Although the beneficial effects of redundant stimulus detection are clearly visible in response latencies, it remains unclear what causes the speed-up of responses. One of the first to observe this effect, Raab (1962), suggested that the redundancy gain effect results from faster detection of redundant than of single stimuli, and thus may reflect an effect operating at perceptual detection rather than response mechanisms. The locus of the redundancy gain effect within the information processing stream has been much debated since that time, and to date no decisive evidence has been provided (see Miller, Kühlwein, \& Ulrich, 2004, and Miller \& Reynolds, 2003, for an overview).

With respect to a perceptual component of the redundancy gain effect, previous research has provided rather contradictory interpretations. Corballis (2002), for example, found that redundancy gain was independent of changes in luminance, suggesting that the effect has no sensory component. Using a stop-signal paradigm, Cavina-Pratesi, Bricolo, Prior, and Marzi (2001) demonstrated that the effect of redundancy gain is located at premotor rather than motor stages. Strong support for a perceptual locus of redundancy gain effects, however, can be derived from a recent study by Murray, Foxe, Higgins, Javitt, and Schroeder (2001; see also Miniussi et al., 1998), who found differences in visual event-related potentials (ERPs) to single versus redundant visual stimuli as early as $75-90 \mathrm{msec}$ after stimulus onset. These very early effects clearly suggest the involvement of a perceptual component.

The aim of the present study was to further investigate the contribution of early low-level perceptual mechanisms to the effects of redundancy gain. Our logic is simple: If the effect of redundant stimulus presentation is at least partially due to an early perceptual component, the manipulation of physical stimulus characteristics should modulate the effects of redundancy gain. For this reason, the participants in the present study were asked to respond to stimuli either appearing on screen (onsets) or disappearing (offsets).

Within the visual attention literature, some have suggested that stimulus onsets and offsets differ in their lowlevel stimulus characteristics and thus engage different encoding mechanisms (e.g., Samuel \& Weiner, 2001), leading to different attentional consequences. A typical finding,

R. Fischer, fischer@psychologie.tu-dresden.de 
for example, is that responses to onset stimuli are faster than those to offset stimuli (Briggs \& Kinsbourne, 1972; Di Lollo, Enns, Yantis, \& Dechief, 2000; Parker, 1980; Wühr \& Kunde, 2006); this finding is known as the onset advantage. Recently, Pratt and Trottier (2005) showed an onset advantage in the generation of reflexive prosaccades (see also Boot, Kramer, \& Peterson, 2005; Brockmole \& Henderson, 2005). Pratt and Trottier demonstrated that appearing peripheral objects, as compared with disappearing peripheral objects, are especially effective at generating reflexive prosaccades, and this finding was independent of luminance changes. Applying a spatial cuing task, Rolke, Ulrich, and Bausenhart (2006, Experiment 1) showed that responses to the offset of a target stimulus are prolonged in an attended versus an unattended condition. At the same time, typical positive cuing effects - that is, decreased RTs in the attended location - were found when responding to the onset of a stimulus (Experiment 2). Further differences between stimulus onsets and offsets in a spatial cuing task were obtained by Pratt and Hirshhorn (2003). These authors demonstrated that offset cues produced considerably earlier effects of inhibition of return (IOR) than did onset cues (see also Gawryszewski, Thomaz, Machado-Pinheiro, \& Sant'Anna, 1994; Riggio, Bello, \& Umiltà, 1998; and Samuel \& Weiner, 2001, for further results of onset-offset investigations in spatial cuing). Hopfinger and Maxwell (2005) conducted an electrophysiological study investigating bottom-up, sensory-driven effects of onset and offset stimuli on subsequent stimulus processing. They found that both abruptly appearing and abruptly disappearing stimuli are capable of enhancing early visual processing in extrastriate cortex. At the same time, however, their study provided further evidence for the uniqueness in processing of abruptly appearing new stimulus events: First, early sensory-evoked ERP components were larger for onsets than for offsets. Second, a specific positivity over central parietal locations was found for stimulus onsets but not for stimulus offsets.

Other examples of the prioritized selection of new elements (associated with bottom-up activations) over old elements in a scene have been put forward by Donk and Theeuwes (2001, 2003; see also Enns, Austen, Di Lollo, Rauschenberger, \& Yantis, 2001). Finally, L. E. Ross and S. M. Ross (1980; S. M. Ross \& L. E. Ross, 1981) showed that visual onset and offset warning signals can lead to dissociable effects on saccade latencies.

Together, these studies suggest that the sudden onset of a stimulus might facilitate perceptual processing, as compared with stimulus offsets, in that different low-level perceptual mechanisms are involved in the detection of onset versus offset stimuli (but see Di Lollo et al., 2000, for an alternative explanation). It has been argued that the sudden appearance of an object has different attentional consequences than the disappearance of an object, and it is generally assumed that a stimulus onset reflects a more potent perceptual event than does a stimulus offset (Pratt \& Trottier, 2005; Samuel \& Weiner, 2001).

A plausible explanation of why the appearance of an object is such a powerful perceptual event has been provided by Yantis and colleagues (Yantis, 1998; Yantis \& Hillstrom, 1994; Yantis \& Jonides, 1996). They argued that the sudden appearance of an object requires the creation of a new visual object representation, because empty visual space is abruptly filled with a new perceptual event. The creation of a new object representation can be seen as a part of the encoding process of onset stimuli that triggers involuntary shifts of attention. In contrast, no new object representation needs to be formed when a stimulus suddenly disappears. In this case, the existing object representation can simply be tagged to indicate that the object is no longer present.

The aim of the present study was to compare the effects of redundancy gain in conditions of stimulus onset versus offset. Because previous studies of redundancy gain had always used abrupt-onset stimuli, it was unclear whether the observation of redundancy gain is strictly a consequence of the bottom-up activation triggered by multiple abruptly appearing stimuli or whether similar redundancy gain effects could also be triggered by the abrupt presentation of any target stimuli, even those involving offsets. If there is indeed any low-level sensory contribution to the effects of redundancy gain, we expect these contributions to be different for offset stimuli than for onset stimuli because, as reviewed above, these types of stimuli are known to have quite different sensory characteristics. Thus, any potential differences in redundancy gain for onset versus offset stimuli would argue for an at least partly perceptual locus of the redundancy gain effect.

We conducted a simple RT (i.e., stimulus detection) task in which participants were asked to respond to the abrupt appearance of stimuli in some blocks of trials and to the abrupt disappearance of stimuli in other blocks. The main question was whether redundancy gain effects would also be observable for offset stimuli and, if so, to what extent. For comparability with several previous experiments (e.g., Miller \& Van Nes, 2007), the participants were asked to respond either unimanually or bimanually in different blocks. In addition to measuring RTs, we also recorded response force parameters as a further dependent variable (Giray \& Ulrich, 1993).

\section{METHOD}

\section{Participants}

Thirty-two students ( 16 female, mean age $=22.2$ years) of the University of Otago took part in the experiment. All had normal or corrected-to-normal vision. The participants attended a single experimental session lasting about $45 \mathrm{~min}$ and received NZ\$7.50 payment.

\section{Apparatus and Stimuli}

The experiment was conducted in a darkened, sound-attenuating booth. The stimuli were displayed on a 17 -in. color monitor that was connected to a Pentium I PC. The stimuli were either one or two square patches (each $1^{\circ} \times 1^{\circ}$ of visual angle) that appeared $8.1^{\circ}$ to the left, to the right, or on both sides of a fixation cross (a plus sign). These stimuli were presented in white with intensities of approximately $70 \mathrm{~cd} / \mathrm{m}^{2}$ against the black background of the computer screen. Participants responded with the index finger of the right hand, of the left hand, or of both hands.

Responses were made by pressing force-sensitive keys, located approximately $30 \mathrm{~cm}$ to the left and right of the body midline, with the left and/or right index fingers. Each response key consisted of a leaf spring $(140 \times 20 \times 2 \mathrm{~mm})$ supported in a clamp at one end, and the participant pressed the other, free end. Strain gauges were at- 
tached near the fixed end so that response force could be measured, in an analogue signal with a resolution of approximately $2.8 \mathrm{mN}$. A force of $15 \mathrm{~N}$ bent the free end of the leaf spring approximately $2 \mathrm{~mm}$. The digitized force signal was recorded at $250 \mathrm{~Hz}$, allowing RTs to be measured to the nearest $4 \mathrm{msec}$.

\section{Procedure}

In blocks using onset presentations, the beginning of a trial was indicated by a small fixation cross in the center of the screen for $700 \mathrm{msec}$, after which zero, one, or two visual stimuli appeared. Participants were asked to respond as rapidly as possible to the appearance of either one or two stimuli and to refrain from responding when no square appeared. If one or more stimuli did appear, the stimuli remained visible until a response was made or until a maximum waiting period of $1,500 \mathrm{msec}$ had elapsed. If no stimulus appeared, the computer also monitored for a false alarm response during the 1,500-msec waiting period.

In blocks in which stimuli were presented as offsets, a trial started with the presentation of the same two squares used in the onset blocks, together with the fixation cross. After $700 \mathrm{msec}$, either zero, one, or two of the squares disappeared. Participants were instructed to respond to the disappearance of one or two of the squares and to withhold a response when the display remained unchanged. After the 1,500-msec waiting period, the disappearance of all stimuli, including the fixation cross, indicated the end of the trial.

The participants were tested in eight experimental blocks. For half of the participants, onset stimuli were presented in the first four blocks and offset stimuli in the last four blocks. This order was reversed for the other half of the participants. Within each set of four blocks, two required unimanual responses (the left or right index finger), and two required bimanual responses (left and right index fingers). The order of unimanual and bimanual responses was balanced across participants.

Within each experimental block, there were four equally likely conditions (20 trials each), depending on the position (if any) of the stimulus onset or offset. That is, in the onset blocks, stimuli appeared on the left, the right, or both the left and right, or did not appear at all. Analogously, in the offset conditions, stimuli disappeared from the left, the right, or both positions, or did not disappear at all.

The experimental design of eight blocks and four positions of onset/ offset (none, left, right, or both) resulted in a total of 640 trials.

\section{RESULTS}

After a preliminary inspection of the RTs, responses with latencies less than $150 \mathrm{msec}(0.6 \%)$ or greater than $1,000 \mathrm{msec}(0.9 \%)$ were excluded as outliers prior to the statistical analyses. Separate repeated measures ANOVAs, including the factors stimulus presentation (onset vs. offset), redundancy (single vs. redundant), response type (unimanual vs. bimanual), hand (left vs. right), and presentation order (onset first vs. offset first), were conducted on RTs and peak force (PF), respectively. The results for RTs and PF are shown in Figure 1.

\section{Response Times}

Responses were clearly affected by redundancy $\left[F(1,30)=18.83, M S_{\mathrm{e}}=2,065.0, p<.001\right]$. In particular, those to redundant stimuli were faster $(347 \mathrm{msec})$ than those to single stimuli $(364 \mathrm{msec})$, reflecting the commonly observed redundancy gain effect. Redundancy gain was much more pronounced when responding to onset stimuli $(26 \mathrm{msec})$ than to offset stimuli $(9 \mathrm{msec})$, producing a significant interaction of redundancy and stimulus presentation $\left[F(1,30)=4.56, M S_{\mathrm{e}}=2,119.5\right.$, $p<.05]$. Further comparisons showed that the advantage

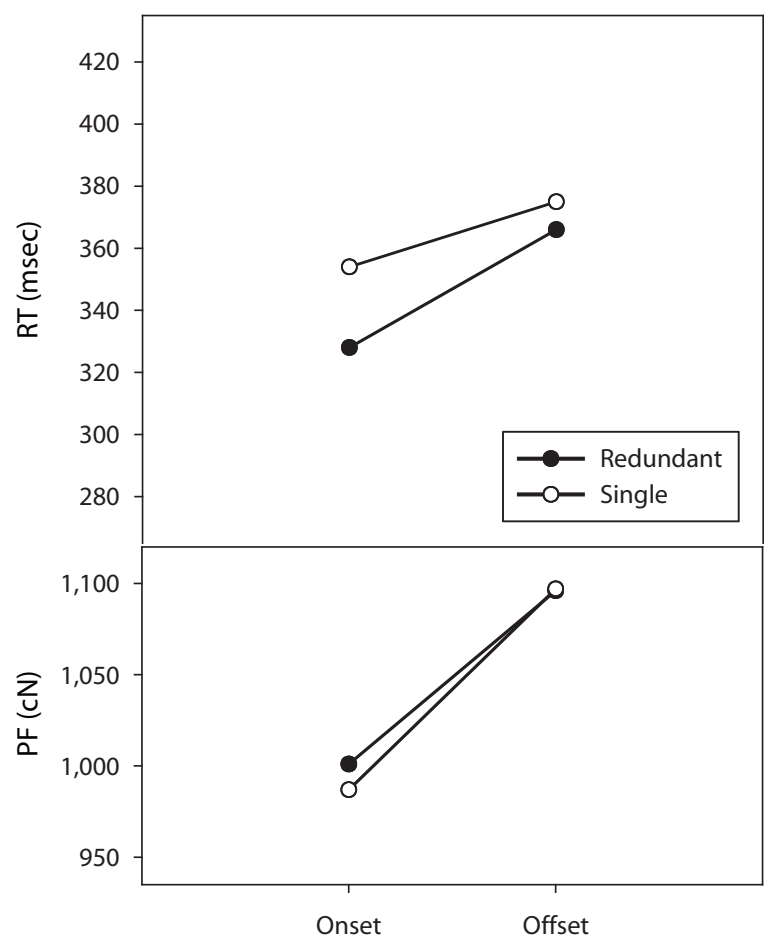

Stimulus Presentation

Figure 1. Response times (RTs, in milliseconds) and peak force $(\mathrm{PF}$, in centinewtons) as a function of stimulus presentation (onset vs. offset) and stimulus type (redundant vs. single), shown in the top and bottom panels, respectively.

of redundant-target stimuli relative to single-target stimuli was not significant with the offset stimuli $[F(1,30)=$ $\left.1.27, M S_{\mathrm{e}}=3,864.9, p=.270\right]$.

Also, redundancy gain was considerably larger for bimanual $(28 \mathrm{msec})$ than for unimanual $(6 \mathrm{msec})$ responses $\left[F(1,30)=22.04, M S_{\mathrm{e}}=694.58, p<.001\right]$, as was also reported by Miller and Van Nes (2007). In addition, the redundancy gain was larger on average for right-hand than for left-hand responses $\left[F(1,30)=4.96, M S_{\mathrm{e}}=260.0\right.$, $p<.05]$, but this pattern was qualified by a four-way interaction between redundancy, stimulus presentation, response type, and hand $\left[F(1,30)=10.11, M S_{\mathrm{e}}=218.19\right.$, $p<.01]$. Post hoc comparisons showed that redundancy gain was larger for right-hand than for left-hand responses only in the condition with unimanual responses and offset stimuli $(p<.005)$, not in the condition with unimanual responses and onset stimuli or in either of the conditions with bimanual responses $(p \mathrm{~s}>.4)$.

Overall, RTs were longer in the offset condition (370 msec) than in the onset condition (341 msec), which was confirmed by the main effect of stimulus presentation $\left[F(1,30)=15.57, M S_{\mathrm{e}}=7,108.2, p<.001\right]$.

Further analyses of the trials with single stimulus changes to the left or right of fixation replicated the usual finding of slightly faster responses with the hand on the same side as the stimulus change, as compared with the hand on the opposite side (see, e.g., Poffenberger, 1912) $[F(1,30)=8.38$, 
$\left.M S_{\mathrm{e}}=540.84, p<.01\right]$. However, this effect did not differ between onset $(M=3.5 \mathrm{msec})$ and offset $(M=8.5 \mathrm{msec})$ stimuli $(p>.15)$. Therefore, we think that this crossed/uncrossed difference for onset versus offset stimuli is unlikely to account for the overall differential effects of redundancy gain for different stimulus presentations.

In order to see whether the observed redundancy gain was consistent with race models (e.g., Raab, 1962), the RT distributions observed with single and redundant stimuli were examined for consistency with the race model inequality (Miller, 1982) using the method described by Ulrich, Miller, and Schröter (2007). With onset stimuli, the race model inequality was significantly violated at the fifth percentile $(p<.001)$, indicating that the gain was too large to be explained in terms of such models. With offset stimuli, however, there were no violations of the race model inequality (all $p \mathrm{~s}>.5$ ), indicating that race models could be entirely responsible for the redundancy gain with these stimuli. In essence, then, these distributional comparisons provide further support for the conclusion that redundancy gain is larger with onset than with offset stimuli, and they eliminate artifactual explanations of this difference based on the idea of greater statistical facilitation for onset stimuli.

\section{Peak Force}

In contrast to the RT data, overall response force did not differ between redundant and single stimuli $[F(1,30)=$ $\left.2.18, M S_{\mathrm{e}}=2,334.5, p=.15\right]$. However, there was a significant interaction between redundancy and stimulus presentation on response force $\left[F(1,30)=5.14, M S_{\mathrm{e}}=\right.$ $1,607.9, p<.05]$. In particular, responses to redundant onset stimuli were executed with more force than were responses to single onset stimuli. In contrast, responding to redundant and single stimuli in the offset condition did not lead to any differences in the applied force (see also Figure 1). In the offset condition, responses were generally executed with more force than in the onset condition $\left[F(1,30)=5.73, M S_{\mathrm{e}}=235,825.2, p<.05\right]$. Also, responses were approximately $8 \mathrm{cN}$ more forceful with the hand on the same side as with the hand on the opposite side of the stimulus change $\left[F(1,30)=9.03, M S_{\mathrm{e}}=\right.$ 907.85, $p<.01]$.

\section{Response Accuracy}

The overall percentage of correct responses was somewhat higher when responding to onsets $(99.1 \%)$ than when responding to offsets $(97.4 \%)\left[F(1,30)=15.7, M S_{\mathrm{e}}=\right.$ $36.445, p<.01]$. Much of this difference was due to a rather high rate of misses $(4.6 \%)$ in the condition with redundant stimulus offsets. False alarms to no-change trials (i.e., no onset or offset) were also more common with offset $(1.9 \%)$ than with onset $(0.6 \%)$ stimuli.

\section{DISCUSSION}

The present study was designed to look for differences in the redundancy gain effect for abruptly appearing (onset) versus disappearing (offset) stimuli, and the results were straightforward. Replicating previous results, strong effects of redundancy gain were clearly found when responses were given to onset stimuli. That is, with onset presentations, responses to two stimuli in the visual field were considerably faster than responses to a single stimulus. In contrast, the redundancy gain effect was significantly smaller with offset stimuli. Indeed, the redundancy gain effect was not even significant in an analysis considering only the offset stimuli.

Because onset and offset stimuli are known to differ with respect to low-level perceptual mechanisms, the observed differences in the effects of redundancy gain for these two types of stimulus presentation indicate the sensitivity of this effect to low-level stimulus characteristics. Such differences also provide support for the idea that early, low-level perceptual mechanisms contribute at least partially to the phenomenon of redundancy gain. Furthermore, the present results provide qualitatively new empirical information regarding the redundancy gain effect, because to our knowledge all previous studies investigating the locus of the redundancy gain effect have used only abrupt-onset stimuli.

The response force data strengthen the conclusion that the redundancy gain effect is different for onset versus offset stimuli. In particular, responses to redundant onset stimuli were executed with more force than were responses to single onset stimuli, but this effect of redundancy on force was not found with offset stimuli, despite the fact that responses were generally more forceful to offset than to onset stimuli. Thus, the reduction of the redundancy gain effect for offset stimuli was also apparent in the force data.

Although onset and offset stimuli do not differ in their quantitative perceptual changes, one critical difference involves the increase and decrease of luminance for onsets and offsets, respectively (see, e.g., Pratt \& Trottier, 2005). For our main purpose, however, this difference is of secondary importance, because luminance would also be expected to have perceptual effects. Most importantly, however, the effects of redundancy gain generally seem not to be affected by changes in luminance (Corballis, 2002), so it is unlikely that our results of decreased redundancy gain for offset stimuli are due to decreases in luminance.

The present finding of larger redundancy gain effects for bimanual than for unimanual responses is in agreement with findings from a recent study by Miller and Van Nes (2007). These authors directly tested predictions derived from Miller's (2004) hemispheric coactivation model of redundancy gain, including the prediction that redundancy gain would be larger with bimanual than with unimanual responses. As the model had predicted, Miller and Van Nes found larger effects of redundancy gain in conditions of bimanual rather than unimanual responses, mirroring our present findings. The finding that redundancy gain depends on the response output also suggests that motor-level mechanisms contribute at least partially to the phenomenon of redundancy gain, as well as the early low-level perceptual processes suggested by the differential effects of onset versus offset stimuli.

A further result of the present study is that, independent of redundant or single stimulus presentation, responses were generally faster and less forceful to onset than to offset stimuli. This onset advantage in RT data is a commonly 
observed finding (Briggs \& Kinsbourne, 1972; Di Lollo et al., 2000; Parker, 1980; Wühr \& Kunde, 2006), although its precise explanation is subject to some debate. Di Lollo et al. (2000), for example, argued that in offset trials, participants may have to inhibit a tendency to respond to the initial onset of the starting stimulus when responding to its later offset is required. This inhibition must later be overcome when the actual disappearance of the offset stimulus requires the execution of the response. The view that the encoding of offset stimuli is associated with inhibitory consequences was also put forward by Samuel and Weiner (2001). In the context of their IOR study, they suggest that object disappearances - unlike object appearances generate fast and early inhibitory effects. They proposed that, although an update of the perceptual representation is also likely for disappearing stimuli, this update requires little, if any, perceptual analysis, because no object to be analyzed has appeared. Our findings of slower and more forceful responses to offset than to onset stimuli are consistent with the idea that some inhibition is produced by presentation of a stimulus to which no response is made. That is, responding to the later offset of such a stimulus requires overcoming this initial inhibition, and thus results in slower and more forceful responses.

Finally, the finding that redundancy gain effects were larger in conditions of bimanual than of unimanual responses speaks against an argument that the size of the redundancy gain effect is negatively related to RTs. Our finding of larger redundancy gains for slower bimanual responses is in accordance with other studies arguing that the effects of redundancy gain are not reduced for large RTs (e.g., Miller \& Adam, 2006; Miller \& Van Nes, 2007). Therefore, we suggest that effects of general response speed are unlikely to account for reduced redundancy gain effects for offset stimuli.

In conclusion, redundancy gain can be reduced or eliminated when early low-level perceptual processing is manipulated (e.g., through onset vs. offset presentation), and this result supports the idea that perceptual mechanisms are at least partial contributors to the effect of redundancy gain (Corballis, 1998; Miniussi et al., 1998). Subsequent research will be needed to specify the exact nature of the perceptual differences responsible for the fact that onsets produce redundancy gains, whereas offsets do not.

\section{AUTHOR NOTE}

This study was supported by a research grant of the G. A. Lienert Foundation to R.F. and by a grant from the Marsden Fund, administered by the Royal Society of New Zealand. We thank Jay Pratt, Peter Wühr, Allison Sekuler, Vincent Di Lollo, Silvia Savazzi, and Carlo Marzi for helpful comments on earlier versions of the manuscript. Correspondence relating to this article may be sent to R. Fischer, Technische Universität Dresden, Department of Psychology, Zellescher Weg 17, 01062 Dresden, Germany (e-mail: fischer@psychologie.tu-dresden.de).

\section{REFERENCES}

Blake, R., Martens, W., Garrett, A., \& Westendorf, D. H. (1980). Estimating probability summation for binocular reaction time data. Perception \& Psychophysics, 27, 375-378.

Boot, W. R., Kramer, A. F., \& Peterson, M. S. (2005). Oculomotor consequences of abrupt object onsets and offsets: Onsets dominate oculomotor capture. Perception \& Psychophysics, 67, 910-928.
Briggs, G. G., \& Kinsbourne, M. (1972). Visual persistence as measured by reaction time. Quarterly Journal of Experimental Psychology, 24, 318-325.

Brockmole, J. R., \& Henderson, J. M. (2005). Object appearance, disappearance, and attention prioritization in real-world scenes. Psychonomic Bulletin \& Review, 12, 1061-1067.

Cavina-Pratesi, C., Bricolo, E., Prior, M., \& Marzi, C. A. (2001). Redundancy gain in the stop-signal paradigm: Implications for the locus of coactivation in simple reaction time. Journal of Experimental Psychology: Human Perception \& Performance, 27, 932-941.

Corballis, M. C. (1998). Interhemispheric neural summation in the absence of the corpus callosum. Brain, 121, 1795-1807.

Corballis, M. C. (2002). Hemispheric interactions in simple reaction time. Neuropsychologia, 40, 423-434.

DIEDERICH, A. (1992). Intersensory facilitation: Race, superposition, and diffusion models for reaction time to multiple stimuli. Frankfurt: Peter Lang.

Diederich, A., \& Colonius, H. (1987). Intersensory facilitation in the motor component? A reaction time analysis. Psychological Research, 49, 23-29.

Di Lollo, V., Enns, J. T., Yantis, S., \& Dechief, L. G. (2000). Response latencies to the onset and offset of visual stimuli. Perception \& Psychophysics, 62, 218-225.

Donk, M., \& Theeuwes, J. (2001). Visual marking beside the mark: Prioritizing selection by abrupt onsets. Perception \& Psychophysics, 63, 891-900

Donk, M., \& Theeuwes, J. (2003). Prioritizing selection of new elements: Bottom-up versus top-down control. Perception \& Psychophysics, 65, 1231-1242.

Egeth, H. E., \& Mordkoff, J. T. (1991). Redundancy gain revisited: Evidence for parallel processing of separable dimensions. In G. R. Lockhead \& J. R. Pomerantz (Eds.), The perception of structure: Essays in honor of Wendell R. Garner (pp. 131-143). Washington, DC: American Psychological Association.

Enns, J. T., Austen, E. L., Di Lollo, V., Rauschenberger, R., \& YANTIS, S. (2001). New objects dominate luminance transients in setting attentional priority. Journal of Experimental Psychology: Human Perception \& Performance, 27, 1287-1302.

Gawryszewski, L. G., Thomaz, T. G., Machado-Pinheiro, W., \& SAnT'Anna, A. N. (1994). Onset and offset of a visual cue have different effects on manual reaction time to a visual target. Brazilian Journal of Medical \& Biological Research, 27, 67-73.

GiRAY, M., \& UlRICH, R. (1993). Motor coactivation revealed by response force in divided and focused attention. Journal of Experimental Psychology: Human Perception \& Performance, 19, 1278-1291.

Grice, G. R., Canham, L., \& Boroughs, J. M. (1984). Combination rule for redundant information in reaction time tasks with divided attention. Perception \& Psychophysics, 35, 451-463.

HoPfinger, J. B., \& MaXWELL, J. S. (2005). Appearing and disappearing stimuli trigger a reflexive modulation of visual cortical activity. Cognitive Brain Research, 25, 48-56.

Miller, J. (1982). Divided attention: Evidence for coactivation with redundant signals. Cognitive Psychology, 14, 247-279.

MilleR, J. (2004). Exaggerated redundancy gain in the split brain: A hemispheric coactivation account. Cognitive Psychology, 49, 118-154.

Miller, J., \& Adam, J. J. (2006). Redundancy gain with static versus moving hands: A test of the hemispheric coactivation model. Acta Psychologica, 122, 1-10.

Miller, J., Kühlwein, E., \& Ulrich, R. (2004). Effects of redundant visual stimuli on temporal order judgments. Perception \& Psychophysics, 66, 563-573.

MiLler, J., \& Reynolds, A. (2003). The locus of redundant-targets and nontargets effects: Evidence from the psychological refractory period paradigm. Journal of Experimental Psychology: Human Perception \& Performance, 29, 1126-1142.

Miller, J., \& Van Nes, F. (2007). Effects of response task and accessory stimuli on redundancy gain: Tests of the hemispheric coactivation model. Journal of Experimental Psychology: Human Perception \& Performance, 33, 829-844.

Miniussi, C., Girelli, M., \& Marzi, C. A. (1998). Neural site of the redundant target effect: Electrophysiological evidence. Journal of Cognitive Neuroscience, 10, 216-230. 
Murray, M. M., Foxe, J. J., Higgins, B. A., Javitt, D. C., \& Schroeder, C. E. (2001). Visuo-spatial neural response interactions in early cortical processing during a simple reaction time task: A high-density electrical mapping study. Neuropsychologia, 39, 828-844.

Parker, D. M. (1980). Simple reaction times to the onset, offset, and contrast reversal of sinusoidal grating stimuli. Perception \& Psychophysics, 28, 365-368.

PoffEnBERGER, A. T., JR. (1912). Reaction time to retinal stimulation with special reference to the time lost in conduction through nerve centers. Archives of Psychology, 23, 1-73.

Pratt, J., \& Hirshhorn, M. (2003). Examining the time course of facilitation and inhibition with simultaneous onset and offset cues. Psychological Research, 67, 261-265.

Pratt, J., \& Trottier, L. (2005). Pro-saccades and anti-saccades to onset and offset targets. Vision Research, 45, 765-774.

RAAB, D. H. (1962). Statistical facilitation of simple reaction times. Transactions of the New York Academy of Sciences, 24, 574-590.

Riggio, L., Bello, A., \& UMiltì, C. (1998). Inhibitory and facilitatory effects of cue onset and offset. Psychological Research, 61, 107-118.

Rolke, B., Ulrich, R., \& Bausenhart, K. M. (2006). Attention delays perceived stimulus offset. Vision Research, 46, 2926-2933.

Ross, L. E., \& Ross, S. M. (1980). Saccade latency and warning signals: Stimulus onset, offset and change as warning events. Perception \& Psychophysics, 27, 251-257.
Ross, S. M., \& Ross, L. E. (1981). Saccade latency and warning signals: Effects of auditory and visual stimulus onset and offset. Perception \& Psychophysics, 29, 429-437.

SAmuel, A. G., \& Weiner, S. (2001). Attentional consequences of object appearance and disappearance. Journal of Experimental Psychology: Human Perception \& Performance, 27, 1433-1451.

Ulrich, R., Miller, J., \& SChröter, H. (2007). Testing the race model inequality: An algorithm and computer program. Behavior Research Methods, 39, 291-302.

WÜHR, P., \& KUNDE, W. (2006). Spatial correspondence between onsets and offsets of stimuli and responses. European Journal of Cognitive Psychology, 18, 359-377.

Yantis, S. (1998). Control of visual attention. In H. Pashler (Ed.), Attention (pp. 223-256). Hove, U.K.: Psychology Press.

Yantis, S., \& Hillstrom, A. P. (1994). Stimulus-driven attentional capture: Evidence from equiluminant visual objects. Journal of Experimental Psychology: Human Perception \& Performance, 20, 95-107.

YANTIS, S., \& JoniDES, J. (1996). Attentional capture by abrupt onsets: New perceptual objects or visual masking? Journal of Experimental Psychology: Human Perception \& Performance, 22, 1505-1513.

(Manuscript received January 12, 2007; revision accepted for publication September 24, 2007.) 